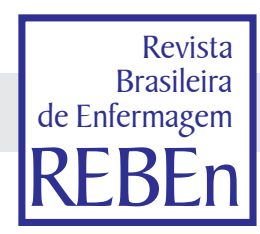

PESQUISA

\title{
Interdisciplinaridade na Graduação em Enfermagem: um processo em construção
}

\author{
Interdisciplinarity in Nursing Diploma \\ Programs: an evolving process \\ Interdisciplinaridad en Programas de Graduación \\ en Enfermería: un proceso en construcción
}

\author{
Marly B. Galindo', Paulete Goldenberg' \\ 'Universidade Federal de São Paulo, Centro de Desenvolvimento do Ensino Superior em Saúde (CEDESS), São Paulo, SP
}

Submissão: 14/03/2007

Aprovação: 02/12/2007

\section{RESUMO}

Os cursos de graduação em Enfermagem, de estrutura disciplinar, se vêm às voltas com a necessidade de reorganização curricular em atenção às exigências legais o Que justifica o objetivo de caracterizar a incorporação da interdisciplinaridade na graduação em três instituições do Município de São Paulo. Adotada uma abordagem Qualitativa, o estudo recorreu à análise documental e entrevistas com os coordenadores de curso. O levantamento evidenciou esforços de reorganização curricular com vistas à integração disciplinar, sendo apontados, ao lado das dificuldades enfrentadas, os cenários de práticas como lócus privilegiado para o exercício da interdisciplinaridade. Descritores: Educação em enfermagem; Programas de graduação em enfermagem; Pesquisa Qualitativa.

\section{ABSTRACT}

Diploma Programs in Nursing with disciplinary curricula cope with the need to be reorganized to conform to the new guidelines. In this way the study aimed at characterizing the incorporation of the interdisciplinarity in tree undergraduate courses, in the municipality of São Paulo. Documents and interviews were collected and then analyzed in a Qualitative approach. The study detected efforts on the part of the coordination of the courses to establish an integrated curriculum. Aside limiting factors pointed out, the projects in the community appear as facilitators of incorporation of the interdisciplinarity in the curricula.

Descriptors: Education, nursing; Education, nursing diploma programs; Qualitative research.

\section{RESUMEN}

Los cursos de graduación en Enfermería, de estructura disciplinar, necesitan reorganizarse en cumplimiento a las exigencias legales actuales, lo que justifica el objetivo de caracterizar la incorporación de la interdisciplinaridad en tres instituciones de la municipalidad de São Paulo-Brasil. Con un abordaje cualitativo, el estudio se utilizó del análisis documental y de entrevistas. El estudio ha evidenciado esfuerzos de reorganización curricular con vistas a la integración disciplinar, siendo apuntados, al lado de las dificultades enfrentadas, los escenarios de prácticas como locus privilegiado para el ejercicio de la interdisciplinaridad.

Descriptores: Educación en enfermería; Programas de graduación en enfermería; Investigación cualitativa. 


\section{INTRODUÇÃO}

As práticas de enfermagem em suas origens eram rudimentares. Só mais tarde emerge a perspectiva científica da prática da enfermagem.Dentro dessa nova racionalidade emerge a necessidade de treinamento formal para disciplinar a conduta da enfermeira $^{(1)}$.

Sem pretender realizar uma incursão na história da enfermagem no país, segundo Santos ${ }^{(2)}$, somente no século XX essa profissão passa a ter maior desenvolvimento, associada ao combate às epidemias. O Departamento Nacional de Saúde Pública, com a cooperação da Fundação Rockefeller, iniciou o serviço regular de enfermeiras visitadoras. $\mathrm{Na}$ época instituiu-se um curso Que daria origem, em 1922, à Escola de Enfermeiras do Departamento Nacional de Saúde Pública, atualmente escola Ana Nery, da Universidade Federal do Rio de Janeiro, implantando no Brasil o sistema de ensino em moldes modernos ${ }^{(3)}$.

Sob a influência do modelo Flexineriano, Que serve de fonte para a reorganização do ensino médico nos $E U A^{(4)}$ são incorporadas as ciências básicas no ensino, ao lado da valorização do treinamento profissionalizante ancorado na assistência, Que resultaria, posteriormente, na segmentação dos currículos em ciclos básico e profissionalizante.

Em meio ao processo de reorganização econômica do pós-guerra, ampliam-se os anseios pela renovação do processo de industrialização, acompanhado da valorização da assistência médica individualizada ${ }^{(5)}$. Renovando a formação do enfermeiro, em 1962. segundo Santos ${ }^{(2)}$, o curso passa a ser ministrado em 3 anos, comportando uma parte pré-profissional, profissional comum, seguido das habilitações em Enfermagem Médico-cirúrgica, Enfermagem Obstétrica ou, em Saúde Pública.

A reforma universitária desencadeada em 1968 demarcaria a instalação dos cursos de pós-graduação, requisito do desenvolvimento tecnológico e da formação de recursos humanos, no contexto do Estado desenvolvimentista do país. No rearranjo subseQüente do ensino da enfermagem, passa a ser valorizada a formação tecnicista, ao lado do desenvolvimento das especialidades - fundamentada no desenvolvimento científico do conhecimento. Neste circuito se cristaliza a cultura escolar marcada pela fragmentação disciplinar, numa estrutura departamental, Que atravessa os ciclos constitutivos do curso.

A incorporação da Sistematização da Assistência de Enfermagem, fundamentada na Teoria das Necessidades Humanas Básicas, segundo a referida autora(2) ${ }^{(2)}$ forformaria um corpo específico de conhecimento, Que consubstanciaria, após anos de luta, a regulamentação da profissão (Lei № 7498/86 e decreto n ${ }^{\circ}$ 94.406/ 87). Este saber retro-alimenta, por sua vez, a movimentação política no sentido de reorganização da assistência, em meio à crise Que se instala no âmbito da saúde, no Quadro de expansão da institucionalização da assistência individualizada.

No contexto da redemocratização do país, a reorganização da assistência se materializa, dentre outros marcadores, na promulgação da Lei Orgânica da Saúde no início dos anos 80, a realização da VIII Conferência Nacional de Saúde em 1986, Que culminaria com a institucionalização do Sistema único de Saúde (SUS), na Carta de 1988. Vislumbrando a superação de uma assistência eminentemente hospitalocêntrica, calcada nas especialidades, a institucionalização do SUS viria renovar os rumos do ensino. Emerge, nesse processo, a preocupação com a formação generalista dos profissionais da saúde, Que seria encampado pelas entidades representativas da enfermagem.

Ante a progressiva globalização da economia, acentuam-se as exigências de formação de um novo profissional, sendo realçada a flexibilidade em detrimento da especialização, a Qual se inscrevia no contexto da delimitação parcelar das funções. Na esteira deste processo, a Lei de Diretrizes e Bases da Educação Nacional ${ }^{(6)}$ define orientações no sentido da reestruturação da educação superior no Brasil, desencadeando acelerada movimentação das instituições de ensino para atender às novas exigências educacionais.

$\mathrm{Na}$ área de enfermagem se instalam os Seminários Nacionais de Diretrizes para a Educação em Enfermagem, reiterando a preocupação com a formação integrada e o perfil generalista, fundamentados no rigor científico, Que se consubstancia, em 200 I , nas diretrizes curriculares nacionais do curso de enfermagem ${ }^{(2)}$. Essas Diretrizes salientam Que as atividades teóricas e práticas, presentes desde o início do curso, devem permear toda a formação do enfermeiro, destacando-se o caráter integrado e interdisciplinar de sua estruturação.

Resguardada a flexibilidade de organização curricular, coloca-se a consideração das disposições institucionais relativas à incorporação da interdisciplinaridade, tendo em vista o delineamento de percursos de sua construção em atenção às exigências legais.

\section{REFERENCIAL TEÓRICO}

Segundo Fourez ${ }^{(8)}$ a interdisciplinaridade é definida, no sentido amplo, como uma interação entre duas disciplinas, Que pode ir da simples comunicação de idéias até a integração mútua de conceitos. A propósito, sem constituir uma escala seqüencial, Pombo(9) considera Que se a multidisciplinaridade constitui, o pólo mínimo de integração, envolvendo justaposição; a transdisciplinaridade constituiria o pólo máximo, pressupondo o compartilhamento de fundamentos comuns, linguagem, bem como estruturas e mecanismos de compreensão do real. A interdisciplinaridade, nas múltiplas variações possíveis entre os dois pólos, envolveria combinações a partir da confluência de pontos de vistas diferentes, envolvendo a formação de uma síntese relativa ao objeto comum.

Considerando Que as disciplinas constituem representações da realidade, Fourez ${ }^{(8,10)}$ acrescenta Que uma disciplina não da conta da aproximação a singularidades históricas das situações concretas - para tanto se faz necessário ultrapassar os limites do conhecimento estandartizados no âmbito das disciplinas. Nessa perspectiva, Fourez ${ }^{(8,10)}$ considera a interdisciplinaridade, no sentido estrito, como a atividade de construção de uma representação da realidade referida a uma situação concreta, Que pressupõe a constituição de um espaço de trocas interdisciplinares, envolvendo a construção de uma racionalidade - Que consubstancia a metáfora por ele denomina de "ilha de racionalidade" ou mesmo "ilhas interdisciplinares de racionalidade". Distinguindo o plano da ação, no âmbito epistemológico, o autor refere a necessidade de levar em conta, nestas aproximações à realidade concreta, o contexto da situação, o projeto em Questão e seus destinatários.

$\mathrm{Na}$ vertente dos autores nacionais, Japiassu ${ }^{(1)}$, pioneiro nos escritos sobre o assunto no país, aponta para a consideração da 
interdisciplinaridade, enQuanto prática individual, como uma "atitude de espírito, feita de curiosidade, abertura, senso de aventura e descoberta”; e, como prática coletiva, pautada pela abertura ao dialogo no trabalho em equipe etc. Fazenda ${ }^{(12)}$, atualizando Japiassu $^{(1)}$, coloca a interdisciplinaridade como uma atitude, um novo olhar, Que permite compreender e transformar o mundo, na busca por restituir a unidade perdida do saber.

Bordoni $^{(13)}$, nessa vertente, caracteriza a interdisciplinaridade pela intensidade das trocas entre especialistas e pela integração das disciplinas num projeto comum, ressaltando o estabelecimento de uma relação de reciprocidade, de mutualidade, ou, melhor dizendo, um regime de co-propriedade, de interação, Que irá possibilitar o diálogo entre os interessados. Ao compartilhar idéias, ações e reflexões, cada participante é, ao mesmo tempo, "autor" e "ator" do processo envolvendo nesse sentido o processo de aprender a aprender. Neste sentido a interdisciplinaridade se situa como porta aberta para os processos transdisciplinares.

Rossi ${ }^{(14)}$, reportando a interdisciplinaridade a um movimento aberto e solidário, considera, numa postura de crítica ao ensino transmissivo e de reprodução de saberes pré-fabricados, a necessidade de pensar a interdisciplinaridade no plano da reorganização curricular, vislumbrando a construção de uma totalidade de significações completa. Machado ${ }^{(15)}$, neste plano de considerações, refere Que o significado curricular de cada disciplina não pode resultar de uma apreciação isolada de seu conteúdo, mas sim do modo como se articulam as disciplinas em seu conjunto.

De acordo com Fazenda ${ }^{(16)}$ trata-se da busca de novos caminhos no complexo e intrincado processo de ensino-aprendizagem Que requer nova postura diante do conhecimento, alicerçada na interação promovida pelo diálogo crítico e reflexivo do saber filosófico. Do ponto de vista metodológico a autora destaca Que o trabalho deverá ser construído pela equipe ao longo do percurso, com reavaliações a cada etapa, respeitando a consideração da interdisciplinaridade eneuanto processo.

Diante da complexidade Que envolve a operacionalização dessas mudanças, Fazenda ${ }^{(12,16)}$ aponta para o risco das disputas disciplinares, chamando a atenção para as resistências associadas ao medo do educador em ver seu saber dividido com outros e de perder seu lugar na instituição - sem falar no despreparo para atuar com a interdisciplinaridade.

Levando em conta as dificuldades Que acompanham a incorporação da interdisciplinaridade, na amplitude conceitual Que encerra, assim como, as potencialidades Que esse movimento comporta, coloca-se a relevância de focalizar, a organização curricular em âmbito institucional, tendo em vista identificar a intencionalidade relativa à incorporação da interdisciplinaridade. Neste movimento, para além do caráter formal do currículo, trata-se de considerá-lo na dimensão política, referenciada, segundo Lucarelli (17) às dimensões do processo de planejamento institucional e resultados alcançados, bem como em relação à participação dos atores sociais (professores, graduandos, etc.) e resultados obtidos junto a cada um desses segmentos.

\section{METODOLOGIA}

O presente estudo adotou a abordagem Qualitativa.

Tendo sido aprovado pelo Comitê de Ética de Pesquisa da
UNIFESP, foram selecionados para o levantamento de dados, cursos de graduação em enfermagem do Município de São Paulo, com currículos de matriz disciplinar, instituídos em diferentes contextos históricos. Contando com a anuência institucional, integraram a casuística do estudo uma escola pública - A, Que inicia suas atividades em 1939, Quando se configura a legislação sobre cursos superiores na área; uma escola privada confessional - B, reconhecida em 1968 , após a Reforma Universitária; e, uma escola privada confessional C, cuja implantação data de 2001, já na vigência das Diretrizes Curriculares.

O levantamento de dados, no plano institucional, se valeu da consulta a documentos impressos, priorizando-se os projetos político pedagógicos, entre outras publicações, ao lado da obtenção de informações junto aos coordenadores de curso. Neste movimento foram coletadas informações sobre a implantação do curso de graduação em enfermagem, missão e objetivos educacionais; estruturação da distribuição das disciplinas na grade curricular com vistas às práticas interdisciplinares, destacando-se a inserção da instituição na comunidade.

Num segundo movimento o estudo se voltou para a identificação das disposições presentes e intenções futuras relativas às condições do exercício da interdisciplinaridade na instituição. Estas informações foram obtidas a partir de entrevistas com os coordenadores dos cursos, gravadas em áudio, cotando com a prévia autorização. A estruturação da entrevista envolveu os seguintes eixos: conceitos e importância atribuída à interdisciplinaridade; a interdisciplinaridade na trajetória institucional; exigências legais de sua incorporação e modificações curriculares em curso; limitações e possibilidades referentes à incorporação da interdisciplinaridade em âmbito institucional.

Registradas as opiniões e as disposições explicitadas pelos coordenadores de curso foi adotada a modalidade de análise de conteúdo, identificadas as unidades de sentido, referenciadas ao contexto relativo à temática em consideração.

\section{RESULTADOS}

\section{Reorganização curricular e interdisciplinaridade}

O Curso de Enfermagem A, criado em 1939, no contexto do Estado Novo, se estrutura na clássica matriz disciplinar. Com a Reforma Universitária abre-se espaço para a pós-graduação. Em 1972 tem início o primeiro curso de especialização, inaugurando a instalação de uma série deles.

O desencadeamento do movimento de reorganização dos serviços de saúde, Que culminaria com a institucionalização do SUS em 1988, incidiria na reorientação da organização do ensino na instituição, no sentido da incorporação da formação generalista. Reafirma-se neste processo a expansão das atividades extra-muros, configurando espaço para a integração disciplinar, junto à formação das equipes multiprofissionais. Compromissados com estas diretrizes, a interdisciplinaridade passa a integrar o temário de debates na instituição desde 1992, norteando o movimento de reconstrução do currículo.

Coincidindo com as disposições preconizadas pela Lei de Diretrizes e Bases da Educação tem início o processo de implantação do novo projeto pedagógico. A constituição de uma Comissão de Estudos do Currículo, contando com a participação de alunos e 
professores, constitui um passo na harmonização de disciplinas em cada área, assistindo o indivíduo dentro de seu ciclo vital, na sua integralidade, nos diferentes níveis de atenção à saúde.

Numa perspectiva gradual de implantação dos novos arranjos curriculares ressalta-se o movimento de reorganização do ciclo básico. De acordo com a coordenadora,

[...] nos primeiros anos, os mais teóricos, os professores em conjunto determinam os objetivos [...] durante todo tempo do curso mesclamos a parte teórica com a prática, mas isto se dá mais especificamente a partir do segundo ano [...]existe também na escola provas articuladas.

O funcionamento do curso da instituição B foi autorizado pelo MEC em 1968, no contexto da abertura do ensino superior às instituições privadas, ratificadas pela Reforma Universitária. Reafirmando a tradição institucional de prestação de serviços, a institucionalização do SUS, em 1988, balizaria o ensino no sentido da formação generalista.

Ao lado do rearranjo da carga horária, o currículo incorpora disciplinas eletivas, flexibilizando as escolhas da parte dos graduandos. O modelo do currículo, entretanto, permaneceu disciplinar - segundo o entrevistado.

A adoção do modelo de ensino interdisciplinar tem sido objeto de estudo na instituição. A possibilidade de uma construção modular se coloca como uma alternativa viável, na medida em Que possibilitaria romper com o programa de disciplinas estaneues.

De acordo com o coordenador:

diante da raiz disciplinar do currículo, entretanto, a interdisciplinaridade é incipiente. [...] ela está presente no envolvimento dos docentes na construção de um planejamento pedagógico integrado. A escola tem a interdisciplinaridade como intenção, porém a prática caminha lentamente.

[...] Na elaboração do projeto pedagógico é intensa a participação do corpo docente e coordenadores de diferentes áreas, contando, em alguns momentos, com a participação dos graduandos, egressos, bem como, junto aos empregadores.

O Curso de Graduação em Enfermagem C, criado em 1995, é reconhecido após sua integralização em 2001. Tendo emergido após a implantação do SUS, o Curso de Enfermagem C, incorpora, em seu Projeto Pedagógico, a formação de enfermeiros generalistas. Buscando atender ao princípio da integração entre a teoria e a prática - já na vigência das Diretrizes Curriculares - as disciplinas profissionais têm inserção a partir do primeiro ano, aumentando, em número e carga horária, ao longo do curso, compostas por áreas temáticas, conforme preconiza o Ministério da Saúde (saúde da criança, saúde da mulher, etc.).

Registrando um movimento de transformações, num primeiro momento, observou-se a redução da duração do curso e a introdução de atividades complementares. Num segundo momento, mantido o mesmo modelo disciplinar, a mudança se dá pela introdução das disciplinas eletivas, sendo o estudante incentivado a buscar saberes outros, Que possam dialogar e/ou complementar os saberes da Enfermagem.

Tendo em vista as Diretrizes Curriculares, segundo a coordenadora do curso:

[...] tentamos fazer de maneira integrada o planejamento de ensino a cada ano. [...] já passamos por mudanças curriculares tentando integrar o ensino de uma maneira interdisciplinar. Nós estamos começando o processo, mas a interdisciplinaridade ainda é incipiente.

Projetos junto à comunidade: um espaço potencial

Destaca-se na dinâmica de reorganização curricular, nas três instituições, a realização de projetos de atuação junto à comunidade, eneuanto espaços Que possibilitariam ao graduando construir um saber articulado nas vivências, no trabalho com o grupo de estudantes, professores e com a comunidade.

Segundo a coordenadora, da instituição A,

[... na escola nós temos o Que chamamos integração enfermeiro docente com enfermeiro assistencial, pois não adianta termos o campo Quando precisamos e depois não termos mais contato com o enfermeiro assistencial. Vale dizer, a propósito, que a diretora do hospital Universitário, assim como, algumas enfermeiras das diferentes unidades fazem parte da Universidade.

Reiterando a tradição institucional de prestação de serviços, o Curso de Enfermagem B, reserva (igualmente) espaço relevante para os trabalhos de extensão. De acordo com o entrevistado, a instituição:

valoriza projetos de atuação junto à comunidade como estratégia de aprendizagem interdisciplinar, tendo em vista possibilidade do exercício do trabalho coletivo e do diálogo. [... I Utilizamos a problematização a partir de conhecimentos e experiência de vida dos graduandos (buscando) aproximar o ensino teórico da prática.

[... Os projetos ocorrem dentro de programas disciplinares, como o de Saúde Coletiva e Saúde da Mulher atuando no Programa de Saúde da Família, de Saúde Mental e outros. Na escola vários enfermeiros atuam no ensino e na assistência. Podemos crescer nisto.

Da mesma forma, a instituição $\mathbf{C}$ destaca a realização de projetos na comunidade como espaços propícios à construção da interdisciplinaridade, em consonância com as modernas práticas participativas. Considerando Que a instituição é referência na região, o Projeto pedagógico assinala a responsabilidade pela gerência do Programa de Saúde da Família. Um grupo de professores responsáveis pelas disciplinas fazem a interface com os enfermeiros nos campos dos diferentes locais de prática, na busca de uma ação integrada.

De acordo com a coordenadora do curso:

Estes projetos constituem espaços de articulação de conhecimentos na vivência dos graduandos. [...] Ainda não se pode dizer Que tenha uma formação $100 \%$ interdisciplinar. $O$ peso da parte específica de enfermagem é maior, mas os 
graduandos têm essa perspectiva de articular o conhecimento. Pesa, na formação desse graduando, a participação de vários outros profissionais.

\section{Limites e possibilidades}

Sofrendo adaptações sucessivas em diversos níveis, a coordenadora do Curso de Enfermagem A refere,

a propósito do desenvolvimento do Projeto Pedagógico, Que a organização das disciplinas no currículo vem passando por mudanças, mas é difícil alterar a estrutura Que estamos vivendo porQue as pessoas não conseguem se adaptar ao novo. Ao lado das potencialidades, associadas à disponibilidade dos docentes para o exercício de práticas interdisciplinares, a coordenadora aponta para a falta de vivência e preparo, no sentido do exercício da interdisciplinaridade.

Dentre as condições limitantes relativas à prática interdisciplinar na instituição, a coordenadora apontou, ainda, a falta de recursos, por exemplo, para transportar graduandos para práticas externas à escola.

No caso do Curso de Enfermagem B, ao lado da dificuldade de sincronização entre os vários módulos, o entrevistado ressalta Que os professores aprenderam de uma forma e é difícil mudar isto tudo.

Acrescenta-se, nestas condições, o fator econômico como condição restritiva à implementação de demandas por mais tempo de atividade dos docentes para participarem de reuniões, para o diálogo e a interação de práticas interdisciplinares. Segundo o coordenador a Escola não tem condições de arcar com o pagamento da carga horária adicional Que seria necessária.

$\mathrm{Na}$ instituição C, há um movimento institucional de preparação para a adoção do modelo de ensino interdisciplinar. Segundo a coordenadora do curso, já fizemos uma primeira tentativa de capacitação do nosso corpo docente. Por outro lado, ela aponta dificuldades em função de um Quadro diversificado de profissionais, cuja inserção e envolvimento nem sempre é regular ou permanente. Nesse sentido, de acordo com a entrevistada, construir junto o projeto interdisciplinar é muito difícil.

A estas considerações somar-se-ia - no espaço da instituição C - a cultura organizacional cunhada pela escola de medicina. De acordo com a entrevistada, trabalhar com a cultura da interdisciplinaridade significa romper paradigmas da cultura médica... isso é muito difíiil; não é impossível, mas dá muito trabalho.

Projetando tendências no sentido da incorporação da interdisciplinaridade, os coordenadores das instituições privadas B e C, chamaram a atenção para as exigências Que acompanham as avaliações do Ministério da Educação e Cultura. A coordenadora lembra Que as diretrizes curriculares, praticamente, obrigam que o projeto pedagógico contemple ações interdisciplinares. Vamos passar por novo reconhecimento do curso no próximo ano; temos Que ter ações interdisciplinares.

\section{DISCUSSÃO}

Em Que pese as distintas injunções institucionais, observou-se, nas três instituições, um movimento de reorganização curricular, atendendo, segundo Rossi ${ }^{(14)}$ e Machado ${ }^{(15)}$ aos requisitos da implementação da interdisciplinaridade.

A despeito das dificuldades enfrentadas e da referência ao caráter incipiente de sua instalação, o movimento de construção de um currículo integrado concretiza a intencionalidade explicitada pelos coordenadores, estabelecendo espaços de diálogos e interlocuções disciplinares. Nesse sentido se aplica o conceito de interdisciplinaridade, referidos ao plano da disposição ou das atitudes, conforme lapiassu ${ }^{(11)}$ ou Fazenda ${ }^{(12,16)}$, dentre outros, ressaltandose sinalizações sobre o caráter processual de sua construção.

Igualmente aplicar-se-ia o conceito amplo de interdisciplinaridade atribuído por Fourez $Z^{(8,10)}$, considerando a interação entre disciplinas, Que pode ir da comunicação de idéias até a integração mútua de conceitos. Vale dizer, neste sentido, Que a busca pela integração na reorganização curricular se inscreve no esforço da construção da multidisciplinaridade. Levando em conta Que ela constitui o ponto de partida para a construção da interdisciplinaridade, conforme coloca Pombo $^{(9)}$, ressalta-se Que este passo também institui uma porta aberta à transdisciplinaridade, conforme coloca Bordoni ${ }^{(13)}$.

Destaca-se nas três instituições a aposta nos projetos de extensão voltados para a comunidade, onde se dá, na prática, o encontro da equipe multidisciplinar. Envolvendo projetos de intervenção em situações concretas, configuram-se, nestes cenários, a oportunidade de aplicação do conceito estrito de interdisciplinaridade, atendendo aos requisitos epistemológicos da construção de ilhas de racionalidade.

\section{CONSIDERAÇÕES FINAIS}

As instituições focalizadas no estudo, evidenciando desenvolvimento diversificado associado à singularidade de suas trajetórias, vêm se mobilizando no sentido da incorporação da interdisciplinaridade, em atenção às exigências das Diretrizes Curriculares.

A intencionalidade de sua incorporação se manifesta na disposição de modelagem gradual de um currículo organizado por áreas temáticas, ao lado de atividades complementares, reservandose espaços de atuação assistencial no âmbito do SUS, entre outras disposições. Sem configurar uma renovação radical em termos de uma formatação fundamentada em novas estruturas paradigmáticas, a reformulação em curso promove espaços de encontros disciplinares, contemplando o caráter processual de sua construção.

Se esta reorganização curricular configura uma condição para o desencadeamento da interdisciplinaridade, destaca-se o papel diferenciado do envolvimento dos professores neste processo. Apresentados como elementos de sustentação do movimento de incorporação da interdisciplinaridade, os coordenadores de curso ressaltam o Quadro de resistências associado ao desconhecimento e despreparo dos docentes.

Dentre os fatores limitantes à incorporação da interdisciplinaridade também foi levantada a Questão econômica, com conotações distintas dependendo da natureza jurídica das instituições investigadas. Foram apontados limites financeiros relativos às necessidades de pagamento dos docentes diante dos requisitos de ampliação da sua permanência, paralelamente à diversidade de regimes de inserção, particularmente, nas instituições privadas. Sem descartar a Questão da disponibilidade 
dos docentes no ensino público, a Questão econômica foi vinculada à rigidez na mobilização de recursos tendo em vista cobrir despesas de custeio das atividades extra-muros.

Valorizando o planejamento como um fim e como um meio da reorganização curricular, com todas as dificuldades Que comporta, a interdisciplinaridade se circunscreve, neste processo, à noção de integração - favorecendo a orQuestração da multidisciplinaridade, eneuanto ponto de partida para a interdisciplinaridade.

Os campos de prática, por seu lado, foram apontados como áreas promissoras de implantação e exercício da interdisciplinaridade, na medida em Que anunciam a possibilidade de desenvolvimento de ilhas de racionalidade interdisciplinar.

Projetando tendências de incorporação da interdisciplinaridade, os entrevistados apontaram para as pressões das avaliações governamentais, particularmente em torno das instituições privadas, cujo credenciamento delas depende.

Diante da premência de ver contemplada a interdisciplinaridade no contexto das mudanças em curso, ressalta-se a ausência de receituários. Levando em conta Que se trata de um processo em construção, as considerações aQui apresentadas, resguardadas nuances conceituais e a multiplicidade de estratégias acionáveis, constituem um convite à reflexão.

\section{REFERÊNCIAS}

I. Almeida MCP, Rocha JSY. O saber de enfermagem e sua dimensão prática. São Paulo (SP): Cortez; 1986.

2. Santos SSC. Currículos de enfermagem do Brasil e as Diretrizes - novas perspectivas. Rev Bras Enferm 2003; 56(4): 36I-4.

3. Oguisso T. A enfermagem no mundo atual e projeções para o futuro. Acta Paul Enferm 2004; 13: 44-5 I

4. Mattos MCl. Ensino médico: o Que sabemos? Interface Comunic, Saúde, Educ 1997; I(1): 193-5.

5. Goldenberg P. Repensando a desnutrição como Questão social. $2^{\text {a }}$ ed. São Paulo (SP): Cortez; 1989.

6. Ministério da Educação e Ciltura (BR). Lei no 9394 de 20 de dezembro de 1996. Fixa as Diretrizes e Bases da Educação Nacional. Diário Oficial da República Federativa do Brasil 1996; seção I, p. I.

7. Ministério da Educação e Cultura (BR). Conselho Nacional de Educação. Câmara de Educação Superior. Resolução CNE/CES No 3, de 7 de novembro de 200 I. Institui Diretrizes Curriculares Nacionais do Curso de Graduação em Enfermagem. Diário Oficial da República Federativa do Brasil 2001; Seção I, p. 37.

8. Fourez G. Fondements épistémologiques pour l'interdisciplinarité. In: Lenoir Y, Rey B, Fazenda I, (editors). Les fondements de l'interdisciplinarité dans la formation à l'enseignement. Paris (FRA): Sherbrooke; 2001 p. 67-84.

9. Pombo O. A Interdisciplinaridade - reflexão e experiência, Lisboa (POR): Texto Editora; 1994.

10. Fourez G. Interdisciplinarité et îlots de rationalité. Rev Can I'enseign Scien Math Techn 200 I; I (3): 34 I-8.

I I. Japiassu H. Interdisciplinaridade e patologia do saber. Rio de Janeiro (RJ): Imago; 1976.

12. Fazenda ICA. A questão da interdisciplinaridade no ensino. Rev Educ Sociedade 1987; 27.

13. Bordoni CT. Pedagogia e educação. Patos de Minas (MG): 2002. [citado em: 18 jan 2005]. Disponível em: URL: http:// www.forumeducacao.hpg.ig.com.br/textos/textos-7.htm

14. Rossi CSM. A proposta da interdisciplinaridade na universidade. [citado em: 15 jun 2005]. Disponível em: URL: http://www.educacaoonline.pro.br/art_proposta_da _interdiciplinaridade.asp?f_id_artig

15. Machado NJ. Interdisciplinaridade e matemática. Rev Prop Fac Educ Unicamp 1993; 4(1-10): 24-34.

16. Fazenda ICA. Interdisciplinaridade: história, teoria e pesquisa. I I a ed. Campinas (SP): Papirus; 2003.

17. Lucarelli E. Currículo. In: Fazenda ICA. Dicionário em construção; interdisciplinaridade. $2^{\text {a. }}$ ed. São Paulo (SP): Cortez; 2002. 